\title{
LA FILOSOFÍA DEL RENACIMIENTO \\ Y EL HUMANISMO SEGÚN THOMAS LEINKAUF
}

\section{THE PHILOSOPHY OF THE RENAISSANCE \\ AND HUMANISM ACCORDING TO THOMAS LEINKAUF}

\author{
Rafael RAMIS BARCELÓ* \\ Universitat de les Illes Balears - Instituto de Estudios Hispánicos \\ en la Modernidad (IEHM)
}

Resumen: El presente escrito muestra algunas claves del monumental Grundriss Philosophie des Humanismus und der Renaissance (1350-1600), de Thomas Leinkauf, al tiempo que comenta algunas de sus hipótesis historiográficas y los hallazgos conceptuales del autor para entender este período.

Palabras Clave: Renacimiento, humanismo, filosofía, Thomas Leinkauf.

Aвstract: The present paper shows some keys of Thomas Leinkauf's monumental Grundriss Philosophie des Humanismus und der Renaissance (13501600), commenting on some of his historiographic hypotheses and the author's conceptual findings to understand this period.

KeYwORDs: Reinaissance, humanism, philosophy, Thomas Leinkauf.

* Edificio Gaspar Melchor de Jovellanos. Universitat de les Illes Balears. Instituto de Estudios Hispánicos en la Modernidad. Unidad Asociada al CSIC. Cra. de Valldemossa, km.7.5, 07122 Palma de Mallorca. E-mail: r.ramis@uib.es 


\section{Introducción}

La publicación de Grundriss Philosophie des Humanismus und der Renaissance (1350-1600) (Hamburg, Meiner, 2017, 2 vols., 1937 pp.) constituye uno de los hitos más destacados de la historiografía filosófica de los últimos años. Parece que tales empeńos reflexivos sean propios de un tiempo ya lamentablemente pasado, y que la producción de nuestros días esté solamente orientada a la publicación coyuntural de artículos especializados. Sin embargo, esta monumental obra de Leinkauf es, a nuestro entender, el esfuerzo filosófico individual más importante que se ha realizado para comprender globalmente el Humanismo y el Renacimiento desde Kristeller y Garin. Por esa razón, no le dedicamos una recensión, sino un review-article, que -por mor del espacio- solo puede tocar algunos de los puntos de interés de esta voluminosa obra. Servirá también como medio para dar a conocer al mundo hispano algunas de sus tesis principales.

Organizamos nuestro estudio en tres puntos. El primero se centra en la estructura, cronología, objeto y fuentes de la obra. El segundo se detiene en el análisis del armazón conceptual y temático. Por último, se hacen una serie de observaciones conclusivas, a fin de que el lector pueda hacerse cargo con mayor profundidad de las implicaciones de este Grundriss.

\section{Estructura, cronología, objeto y fuentes}

Se trata de una obra cuyo título es ya revelador, pues subraya que trata (conjuntamente) la "Filosofía del Humanismo y del Renacimiento". Frente a quienes (como Kristeller y sus discípulos Ronald G. Witt o Robert Black) consideran este período como una mera época de transformación -o de continuidad literaria- entre la Edad Media y la Moderna, con escasas repercusiones filosóficas, para Leinkauf se trata de una etapa con verdadera significación filosófica y, como veremos, se esfuerza por mostrar su arquitectura conceptual. El título indica también la cronología (1350-1600), que, frente a las pretensiones de Kristeller (1300), retrasa algo el punto de arranque, y concuerda con la mayoría de autores, al situar su fin en 1600.

La obra se divide en diferentes secciones: tras una larga y elaborada introducción (250 pp.), se alternan estudios sobre grandes áreas temáticas con análisis de las tres figuras que Leinkauf escoge como puntos de referencia. Así, dedica unas secciones a Sprache (Lenguaje), Ethik (Ética), Politik (Política), 
Historik (Historia), Schönheit und Liebe (Belleza y amor), Naturphilosophie und Naturtheorie (Teoría y filosofía de la naturaleza), Seelenlehre und Methodenreflexion (Psicología y métodos de reflexión). Los autores que elige para profundizar son Petrarca, el Cusano y Ficino.

Aparentemente, podría parecer una obra en la que la filosofía teorética brilla por su ausencia, aunque veremos que no es exactamente así y que la estructura interna depende de la metafísica y la epistemología. Por lo tanto, Leinkauf no vindica el Renacimiento como época de filosofía debole, sino como tiempo de transformación de viejas ideas, y de concurrencia de otras nuevas, con notables implicaciones tanto en ontología, teodicea y gnoseología, como también en filosofía práctica, el trivium, el quadrivium, la filosofía natural, y la estética.

En el prólogo se cita, de entrada, The Cambridge History of Renaissance Philosophy (1988), obra coral que Leinkauf contrapone a la individual de Ernst Cassirer (1927). Estos son tal vez los puntos de referencia primarios del autor que, junto con Kristeller y Garin, representan los ejes historiográficos centrales con los que dialoga. Mientras que The Cambridge History (en la que convivían autores de orientación muy dispar) eludía deliberadamente las cuestiones de método, yuxtaponiendo a filósofos con científicos y estetas, escolásticos con antiescolásticos..., $(1988,5)$, Cassirer se concentraba en la Modernidad y vindicaba que el individuo y el cosmos eran los centros de la "filosofía" del Renacimiento. Con ello se oponía a Burckhardt, quien negaba la entidad filosófica de este período, mientras que Garin hacía lo posible por conectar admirablemente el Renacimiento y el Humanismo como modo di vita con la expresión filosófica de problemas, conceptos e inquietudes.

Leinkauf pretende tomar lo mejor de todos, valorando el Renacimiento no sólo como historia intelectual (Cantimori, [1932], 1985), y trascendiendo la visión libresca y erudita de Kristeller, para defender una "Filosofía del Humanismo y del Renacimiento" de cuerpo entero, en la que caben tanto las antiguas disciplinas como las nuevas. Para autores como Eusebi Colomer, lo fundamental de esta época no era tanto el cultivo de la sabiduría clásica, sino su auténtica "restauración” (Colomer, 1997, 10), mientras que, para Miguel Ángel Granada, el Renacimiento era el "hecho cultural fundamental en los siglos XV y XVI” (Granada, 2000, 48), con enormes implicaciones tanto en el pensamiento tradicional, como sobre todo en el renovador, especialmente con la creación de la nueva ciencia. Para Leinkauf, es una época de nuevos equilibrios conceptuales, que se traducen en formas de expresión filosófica, que reinterpretan el mundo 
antiguo, se confrontan con el mundo medieval con el que -en buena parteconviven, y crean, por reacción, oposición o complementariedad, nuevos conceptos y disciplinas que abren la Época Moderna.

Resulta muy sorprendente que Leinkauf no cite The Cambridge Companion to Renaissance Philosophy, volumen editado por James Hankins, en cuya introducción explicaba que pretendía enfatizar el dinamismo y el pluralismo de la filosofía renacentista, en "su búsqueda de las nuevas perspectivas filosóficas, así como la transformación y radicalización de las tradiciones escolásticas heredadas de la Edad Media” (2007, 7). Esta obra quería mostrar que la filosofía renacentista tenía un pie en el Medioevo, que renovó, y otro en la Modernidad, que preludió. Quizás Leinkauf considere que este compendio no altera ni la perspectiva ni los resultados de The Cambridge History... Añadamos que recientemente se ha publicado The Routledge Companion to Sixteenth Century Philosophy (2017) en la que los editores, H. Lagerlund y B. Hill, buscan romper con el concepto de "Renacimiento", a fin de dar relieve a algunas cuestiones propias del siglo XVI, como la segunda escolástica, los jesuitas...

Volvamos al Grundriss. Para definir Humanismus, Leinkauf busca definiciones de Kristeller (1961, 9-10) y Garin. Del primero toma dos ideas: 1) el humanismo como una disposición intelectual basada en el estudio retórico y gramatical de los textos antiguos para establecer un canon, y 2) la continuidad del humanismo con la experiencia mística medieval y la interioridad agustiniana y su discontinuidad con su doctrina sobre el mundo y en la igualdad de condiciones entre trascendencia e inmanencia. Según Garin, el humanismo es una disposición intelectual que articula un canon de disciplinas, las cuales reflejan la esencia de la humanidad y tienen una orientación esencialmente práctico-moral (I, 115-116).

Leinkauf busca una síntesis de las tres: "aquí aparecen juntos los aspectos de las tres primeras definiciones: lenguaje, moralidad, ciencia” (I, 118). Esta suma entre las artes liberales, la dimensión ético-política y el conocimiento de lo sensible y lo suprasensible sería la base de la filosofia del humanismo. Se trata de una solución aparentemente ecléctica que, sin embargo, supone un avance al fundir en un crisol común enfoques supuestamente dispares. Con todo, el trabajo de Leinkauf sobre el análisis de fuentes (impresas) y su empeño en mostrar las continuidades (y discontinuidades) entre Edad Media Renacimiento - Época Moderna, en una perspectiva de longue durée, le apartan de la búsqueda archivística, de la edición de manuscritos y de la visión gariniana 
del Renacimiento como fenómeno de vida. Tiene, en este sentido, más vínculos metodológicos con el análisis de Kristeller, que privilegia la exploración de un conjunto de textos tomado como canon.

Sin embargo, el hecho de que Leinkauf se haya dedicado al diálogo entre la filosofía renacentista y la moderna, con notables trabajos sobre Kircher, Schelling, el Cusano o Leibniz le da mucha libertad temática y expositiva, puesto que no defiende un "terreno propio" de especialista, como tantos otros estudiosos del Renacimiento, sino que pretende concretar los perfiles de una época en el continuum de la historia de la filosofía. Tal vez esa sea la razón del constante diálogo entre lo que tradicionalmente ha sido entendido como Humanismo y Renacimiento con la Escolástica. Entre las dificultades que subraya Leinkauf para delimitar los conceptos de Humanismus, Renaissance y Frühe Neuzeit, muestra sobre todo la convivencia de estas etiquetas con la lánguida escolástica nominalista y con la renovación que llega hasta Suárez (I, 15-17).

A diferencia de lo que sucede en The Cambridge Companion o en The Cambridge History (en la que conviven, por ejemplo, la lógica y la filosofía natural "tradicional" con la "nueva"), Leinkauf recuerda que, desde Petrarca hasta Bruno y Descartes, la filosofía humanística se desarrolla en confrontación y diálogo con la escolástica. No se trata, con todo, solo de la escolástica de los siglos XII a XIV, que tantos autores del XV consideraron bárbara, sino también de su (renovada) continuidad en los siglos XV y XVI. Con todo, para Leinkauf, los "humanistas" dialogan con los escolásticos pasados y presentes, con un influjo recíproco mucho mayor de lo que habitualmente se indica. De ahí que entienda que si Descartes deviene el gozne epocal en el debate entre humanistas y escolásticos (como muestra Copenhaver en The Routledge Companion, 2017, 7-53), en la formación de su filosofía intervienen tanto Suárez o el agustinismo, como Galileo o Ramus; o que Suárez dialogaba no sólo con la tradición y sus coetáneos, sino también (de forma muy sutil) con problemas "humanísticos" (I, 17-19).

Sobre el diálogo de los humanistas con la tradición grecolatina y Patrística, Leinkauf hace comentarios verdaderamente elocuentes y divertidos, por ejemplo, sobre la elaboración del Secretum de Petrarca, y de su interpretación interesada de San Agustín (I, 125). Los humanistas, como reconoce Leinkauf, releyeron la tradición interpretándola de forma a menudo capciosa, de manera que no sólo se dedicaron a la edición cuidadosa, sino también a la (elegante) distorsión, a fin de lograr sus objetivos. 


\section{Conceptos y temas}

El tránsito de la Edad Media al Renacimiento y el Humanismo se da a partir de cuatro grupos de "Irritationen" (I, 28), es decir, de cuatro crisis o desgarros del statu quo, que -según Leinkauf- son: (I) la potencia absoluta de Dios, la contingencia del mundo y el nominalismo (ca. 1320-1550); (II) la muerte, la peste, la angustia (1347-1351); (III) la exploración del mundo y la propuesta copernicana (ca. 1450-1550); y (IV) la Reforma (1517-1600).

Así como las tres últimas han sido tratadas con detalle por la historiografía (Huizinga, Kuhn, Koyré...) y han marcado los lugares clásicos del tránsito de una época a otra, la primera merece un tratamiento algo más detallado, pues trata las circunstancias más filosóficas (en un sentido tradicional). Leinkauf, en la Irritation I, traza un cuadrado ontológico-epistemológico, del que indica: "este cuadrado se usa con fines heurísticos, y aparecerá en este libro una y otra vez con la función de aclarar” (I, 39):

\section{Essentia (a)}

Res (b) Verba (b')

\section{Existentia (a')}

En la relación entre a y a’ se estudia la relación entre la forma esencial y la realidad en cuatro dicotomías que muestran la tensión entre los puntos centrales de la ontología y la teodicea: (i): Dios - la creación / el mundo; (ii): necesidad - realidad / contingencia; (iii): universal - singular; (iv): gracia - subsistencia / revelación. La relación entre b y b’ muestra la tensión ontológica y epistémica entre res y verba, en una confrontación del modelo clásico humanístico y el discurso lógico escolástico, en cuatro dicotomías: (i): sustancia (realitas) dialéctica; (ii): realidad - opiniones; (iii): realidad - ficción; (iv): vida - concepto (I, 39).

El cuadrado permite otras tensiones (co)laterales, no menos importantes: entre res - existentia $(\mathrm{b}-\mathrm{a})$ o verba - essentia $(\mathrm{a}-\mathrm{b}$ '), espoleadas por el nominalismo y que favorecieron un desplazamiento desde la ontología hacia lo lingüístico y lo gnoseológico, al tiempo que la tensión entre existentia (a') y verba (b') tuvo notables implicaciones a raíz de la Reforma, por ejemplo, en temas de teología sacramentaria. Concluye Leinkauf, entre muchas otras cosas, que el 
giro humanístico-dialéctico de la sustancia y del ser en su relación lingüísticosimbólica y emocional-afectiva, tuvo consecuencias tanto ontológicas, lógicodialécticas como teológicas (I, 40).

Recalcando la importancia del nominalismo en la disolución de la escolástica, Leinkauf considera que hay una reestructuración de las formas esenciales (a b'), las cosas (b-b') y la realidad (a'- b') (I, 43). Y se dio una triple consecuencia que abrió el camino a las otras dimensiones de esta primera Irritation: 1) la de los conocimientos (en sus formas más elevadas como Dios), 2) la de su "coseidad" y 3) la de su existencia contingente (en su unicidad) (I, 46).

Las cuatro "irritaciones" promovieron, en fin, un marco humanístico caracterizado por tres dimensiones: 1) la dignidad, 2) el saber y la ciencia, y 3) la técnica e innovación. En cuanto a la primera, se refiere al rasgo más comentado de este período: la dignidad del hombre, que es el centro del mundo, y de su capacidad de hablar, escribir, hablar y conocer. La segunda alude a cuestiones epistemológicas: el tipo de saber intuitivo frente al lógico-escolástico, la relación entre saber y querer, la cuestión del método, debatiendo a Aristóteles con las tendencias axiomáticas de Euclides y el enciclopedismo de Llull -con un apartado concreto dedicado a Jacopo Zabarella, comentarista aristotélico- y su proyección hacia la universalidad (que lleva desde el cultivo de los saberes humanos hasta la idea de enciclopedia). La tercera enfatiza la innovación y la técnica: la perspectiva, la imprenta, el estudio anatómico y el telescopio, perfeccionado por Galileo.

No podemos seguir analizando el entramado conceptual, que tiene gran riqueza de detalles, y que el lector interesado podrá analizar recorriendo estas páginas introductorias, llenas de sugerencias y comparaciones. Pasemos ya a una descripción de las cuestiones temáticas, en las cuales -como ya hemos dicho-se hace una presentación que alterna un examen por materias y un análisis más detallado de los pensadores elegidos.

El primero de ellos es Petrarca, tal vez el autor con más relieve en la obra, a quien se le dedica toda una sección y que vuelve a comparecer en diversas ocasiones en el estudio temático. Como todos los estudiosos del Renacimiento, Leinkauf siente predilección por Petrarca, de quien analiza su "yo" como autor, y su proyección ética, poética, epistémica y como manifestación del amor. Seguidamente considera su concepción del mundo: la multiplicidad, el humanismo, la dignidad humana y su postura ante la muerte. El último aspecto 
analizado es la recepción de la teología y su concepto de Dios. Para Leinkauf, Petrarca es la puerta a través de la cual se asoman los nuevos temas y enfoques humanistas, que serán desarrollados por los autores siguientes, en un diálogo permanente con el poeta de Arezzo.

El primer tema que trata de forma monográfica es Sprache. Tras analizar el problema del latín y de las lenguas vernáculas como forma de expresión, desarrolla cuatro corrientes: la batalla entre la gramática y a la dialéctica (como lógica), con un breve estudio de Salutati, Valla, Agricola, Lefevre, Erasmo, Vives, Ramus y Nizolio; la theologia poetica, de nuevo con Petrarca y Salutati, y también Boccaccio, Bruni y Poliziano; la idea platónica del poeta creador, con Ficino y Landino, y su transformación como furor en Francastoro o Bembo; y la tradición poético-retórica de Aristóteles, con los criterios poéticos como forma de creación.

El segundo tema es la ética. Leinkauf estudia los grandes conceptos (bien, virtud, voluntad y libertad) y lleva a cabo una clasificación muy interesante de proyecciones éticas: la del bien común y la virtud (Salutati, Bruni, Pomponazzi); la voluptuosa (Valla, Cosma Raimondi); la del amor y la contemplación (Ficino y discípulos), la del miles christianus (Erasmo, Vives, Lutero); la del cálculo y utilidad (Maquiavelo), la cortesana (Castiglione) o la de los individuos heroicos (Bruno). El último apartado es un estudio de la absorción de algunos de estos ideales por parte de la escolástica, especialmente desde Vitoria a Suárez (I, 778795).

El tercer tema es la política, que -pese a no formar parte de los studia humanitatis- analiza desde los precedentes de Dante y Marsilio de Padua hasta la idea de soberanía en Bodin, pasando por Salutati y Maquiavelo, a quienes dedica gran atención, al igual que a las ideas opuestas: la política cristiana, el platonismo político de Francesco Patrizi, la función política de la religión en Cardano y las utopías (especialmente de Moro y Campanella).

El cuarto y último tema monográfico de este bloque es la historia, vista como fenómeno de esta época. Es especialmente destacado el análisis conceptual que hace a partir de los estudios contemporáneos sobre la historia como verdad y saber, las implicaciones cristianas de la historización, la dimensión antropológica de la misma y su estructura conceptual: secuencialidad, temporalidad y orden. Tras analizar el concepto de inicio, analiza los factores y los criterios de la historización: verdad, objetividad, universalidad, sinceridad, incompletud, 
inconstancia, libertad y utilidad. Leinkauf concluye este capítulo (uno de los más novedosos por su penetración reflexiva) con ejemplos: la historia como estructura cultural (Petrarca), historia documental urbana (Bruni), quasi soluta poesia (Pontano), autoexpresión antropológica (Patrizi) o como método de reflexión sobre la historia misma (Bodin).

El segundo volumen comienza con sendos estudios dedicados a autores: Nicolás de Cusa y Ficino. Leinkauf destaca, ante todo, el carácter sistemático de ambos. Frente a las aportaciones más concretas y sectoriales de algunos de los pensadores antes expresados (Maquiavelo, Bodin, Patrizi, Nifo, Erasmo, Valla...) tanto el Cusano como Marsilio son filósofos con un sistema completo de pensamiento, tal y como lo habían sido muchos de los medievales o lo serán casi todos desde Descartes a Hegel.

El tema dedicado a Nicolaus von Kues inicia con un análisis de sus fuentes e influencias, y lo desarrolla en dos partes. La primera dedicada al saber y al concepto de espíritu, y al método, para desplegar finalmente su Grundtheoreme de la coincidencia (de los opuestos). La segunda empieza desde Dios, explicando los nombres de Dios y los conceptos de trascendencia e inmanencia, para pasar a la relación de Dios con el mundo, la estructura interna y la externa del mundo. Finalmente se analiza, por un lado, la antropología y, por otro, la cristología, para terminar estudiando las implicaciones que tienen en su pensamiento.

En el caso de Ficino, se remarca que no sólo tradujo a Platón, sino que lo repensó y que configuró un "platonismo" nuevo. El sistema de Marsilio estaba basado, según Leinkauf, en la unicidad, en la distinción entre el intelecto de Dios, el del ángel (Plotino) y el del hombre, la doctrina sobre el alma, la materia y la belleza (o el arte). Se estudia a Ficino como autor de un platonismo cristiano, a través de una síntesis entre la teología judeocristiana y pagana. Leinkauf concluye mostrando las relaciones entre filosofía y teología, y su influjo posterior.

El tema consagrado a la belleza y al amor es una síntesis muy eleborada de la estética humanista en un sentido amplio (que no se halla, por ejemplo, en The Cambridge History, más vencida hacia los temas "tradicionales" de la filosofía). La unidad y multiplicidad de la belleza es analizada en Diacceto, León Hebreo y Bruno, mientras que la tradición del amor arranca en Sabunde y llega hasta Agostino Nifo, pasando por los autores antes mencionados, Bembo, Patrizi y otros. 
El último tema es el más largo y quizás el más complejo: la filosofía natural, la doctrina acera del alma y los métodos de reflexión. Abarca desde el quadrivium, pasando por la física hasta llegar a la psicología. Tras la definición de los conceptos de naturaleza, alma, y el examen de los métodos (autopsia, experimento, inducción), Leinkauf pasa al estudio de la cosmología y astronomía copernicana, la función teorética-natural de la astrología y la relación entre la magia, el hermetismo y la alquimia. Tras analizar las continuidades y discontinuidades de la ciencia natural medieval y renacentista, se detiene en la Escuela de Padua, con Biagio Pelacani, Paolo Veneto y Pomponazzi, a la cabeza. La obra concluye con la "nueva física" del siglo XVI, con Telesio, Patrizi y Campanella, examinando los cambios en los conceptos de espacio, en la cantidad y la calidad, la potencia y el movimiento, y las doctrinas de Francastoro. Se dedica un último apartado a la doctrina de los mundos infinitos de Giordano Bruno, que bien podría entenderse como el final de una época.

\section{Observaciones finales}

Leinkauf acaba su obra con una serie de conclusiones, entre las que destacamos los cambios que, a su juicio, se habían producido gracias a las cuatro irritaciones: los equilibrios entre trascendencia e inmanencia (con un creciente papel de la segunda), la cohabitación de diversas respuestas (platonismo, neoplatonismo, aristotelismo, atomismo...) en los diferentes autores y, en definitiva, el eclecticismo propio del período, que el autor ve cíclico y cada vez más orientado hacia lo inmanente y lo "horizontal". Con todo ello se iba vigorizando cada vez más el individuo, el cual era el centro del cosmos, y que podía conocer, e iniciar una nueva relación con la divinidad, hecho que tenía asimismo importantes consecuencias políticas.

El tiempo entre Petrarca y Bruno, Boccaccio y Suárez, Salutati y Campanella, y entre el Trecento y final del Cinqueccento (e incluso comienzos del Seicento), al decir del autor, es filosófico, aunque no pueda ser calificado con unas pocas etiquetas (II, 1757). Para Leinkauf, en fin, la filosofía del Humanismo y del Renacimiento puede ser entendida como un conjunto complejo de discursos paralelos, que tienen una relación especialmente cercana a la teología, que intenta transformar.

Hasta ahora la filosofía del Renacimiento era vista a menudo como un haz de tendencias nuevas yuxtapuestas y contendientes contra la escolástica. De ahí que el principal propósito de la obra, según el autor, haya sido mostrar las 
relaciones de dichos discursos entre sí (ética, política, ciencia...), al tiempo que se enfatiza la correlación de estas facetas del humanismo con la filosofía tradicional que se hacía a la sazón. Creemos que el mayor mérito de Leinkauf es haber mostrado la necesidad de trazar una historia unitaria y dialógica de la filosofía del Renacimiento, exponiendo sus conexiones internas y externas. De ahí, que sea obligado detenerse a identificar la ontología y la epistemología subyacente. Por eso, compara a la vez autores y corrientes, se subrayan puntos de partida, coincidencias... y se enfatizan las tendencias tardohumanistas que originaron los grandes movimientos del siglo XVII (el racionalismo, el enciclopedismo...) No esconde que se trata de un proyecto demasiado amplio para ser abordado (de momento), si bien tenemos que calificar su esfuerzo individual como un punto de referencia historiográfico, que marca buena parte del quehacer intelectual a partir de ahora.

La concepción de Leinkauf nos parece muy acertada en términos generales y creemos que hubiera sido muy difícil que un "especialista" en el Renacimiento hubiera logrado una hazaña de calibre similar, especialmente porque el profesor alemán otorga relieve a autores y problemas de acuerdo con su dilatada experiencia como autor "modernista". Huye de los debates tradicionales entre continuidad y ruptura, propios de los medievalistas y expertos en el Renacimiento. Sus investigaciones, por ejemplo, sobre el enciclopedismo (de Alsted, Comenius, Izquierdo -al que llama Stefano, en vez de Sebastián- o Yves de París) le permiten considerar la riqueza del ramismo o el lulismo, al tiempo que valora el protagonismo de la escolástica en la formación de estos autores (II, 1739) y de sus precedentes en el siglo XVI.

Ciertamente, en los siglos XV y XVI, humanistas y escolásticos se daban formalmente la espalda, aunque no se perdían de vista en absoluto. El nominalismo y la "Segunda Escolástica" contribuyeron a forjar -en muchos casos, qué duda cabe, por oposición y confrontación- los temas y problemas de los humanistas, que dialogaron indirectamente con la "filosofía oficial", mientras que los maestros universitarios más sagaces no se desentendían de las cuestiones suscitadas por los humanistas desde sus academias o cenáculos. Había también numerosos casos híbridos, propios de esta época sincrética, que armonizaban tendencias escolásticas con humanísticas, como Andreas Canter o Heymericus de Campo, que no aparecen en la obra.

Sin embargo, aunque la escolástica esté presente en el pensamiento de Leinkauf, no hay apartados dedicados específicamente a ella, pues quiere 
romper algunas barreras presentes en The Cambridge History, en The Cambridge Companion, con la aportación de John P. Doyle sobre la "Hispanic Scholastic Philosophy" (2007, 250-269) o en la novedosa The Routledge Companion, muy sensible a la escolástica como un eje central de la filosofía del siglo XVI. Con todo, quizás hubiera sido más revolucionario discutir si Vitoria o Las Casas pueden ser considerados "humanistas" o "renacentistas" (en el sentido de que dan un giro hacia el hombre o si hacen "renacer" con otras sensibilidades y en otras direcciones la escolástica del siglo XIII tras su "barbarización” nominalista; véase, desde una perspectiva teológica, Belda Plans, 2000). En este sentido, hay que plantearse si podría superarse, por ejemplo, la contraposición de Garin (1987, 186-191) y otros entre educación humanística y educación jesuítica, para dar un sentido unitario a las estructuras mentales de la época.

No es que Leinkauf señale una yuxtaposición temática y una coexistencia de filósofos "oficiales" con "transgresores", científicos, políticos y reformadores religiosos -como puede verse en The Cambridge History o en exposiciones como la de Gandillac (1974)-, sino que se buscan las claves de una época tomada como un uno-todo, en la que los "humanistas" son los solistas y los escolásticos, el bajo continuo (o, tal vez, el contrapunto). Al leer el Renacimiento desde la Modernidad, Leinkauf es capaz de revelar algunas de sus estructuras más profundas y de prestar atención a ciertos detalles que, de otra manera, hubiesen pasado inadvertidos.

Así como sería imposible buscar una definición o un método unitario para estudiar el Renacimiento a partir de los trabajos de Wallace, Poppi, Wickers o Popkin (que conviven en The Cambridge History), Leinkauf se preocupa mucho por la unidad metodológica. Ciertamente, dedica numerosas páginas al Renacimiento "italiano", aunque no tiene esa pasión etnocéntrica que contagian los estudios, por ejemplo, de Garin, ni ese equilibrio entre lo anglosajón y lo italiano que también puede hallarse en Il Rinascimento italiano e l'Europa (vol. I, 2005), obra que, en muchos puntos, consagra un status quaestionis. El profesor alemán, en este punto, es rupturista al plantearse el Renacimiento y el Humanismo como un fenómeno filosófico, aunque no en sí mismo, como se hace a menudo, sino en comparación con las épocas anterior y posterior. Y frente a la visión que entendía el Renacimiento como una época de luz que, tras atravesar algunos nubarrones, llegaba a la Ilustración, Leinkauf muestra un Renacimiento con claroscuros: a menudo las (pretendidas) luces no se podían apreciar con la debida precisión sin las "sombras". Era Naphta quien sacaba lo mejor de Settembrini. 
La lectura "ilustrada" del Renacimiento -que puede verse en obras de Holmes o Hazard, y que contaba con el beneplácito de Garin $(1981,47)$ - tuvo su primer contrapunto en The Cambridge History-acrecentado y desarrollado en nuestros días por The Routledge Companion- y alcanza ahora su correctivo en la óptica de Leinkauf, quien confronta algunos aspectos "dionisíacos" del Barroco y el Romanticismo como atenuantes de los autocomplacientes estudiosos del "apolíneo" humanismo. Con ello se subrayan las brumas, el paisaje tras la copiosa lluvia aristotélica del siglo XVI (que Schmitt y Lohr describieron), las auroras y los atardeceres. La interpretación selectiva de Leinkauf se centra, sin duda, en el Renacimiento italiano, aunque lo hace alla tedesca. No irradia el optimismo de Garin, ni Vasoli ni tantos otros seguidores suyos, filósofos, que al tiempo son historiadores y filólogos, en cuyas páginas se huele el perfume de los manuscritos de aquella italianità irrenunciable, aunque tampoco es una obra de biblioteca y flexo, como las de Kristeller y sus discípulos. En ella hay vida, pasión, amor, ética y estética (la atención al arte en este libro es muy refinada), aunque también ontología, epistemología, política, psicología y ciencia: es la visión de un alemán enamorado de Italia, que toma una postura hermenéutica, la cual le permite contemplar el paisaje a la debida distancia, sin perder detalle, aunque sin retozar al sol nella piazza.

Mientras en la obra se dan la mano Rinascimento e Umanesimo con Frühe Neuzeit, queda algo más deslucida la Renaissance. Es obra poco francesa, en la que los protagonistas más celebrados en otras obras tienen un papel secundario $\mathrm{o}$ incluso no aparecen. A diferencia de Popkin (y al igual que sucede en The Cambridge Companion), los escépticos, desde Montaigne a Sánchez y Charron, tienen una muy escasa consideración en esta obra. Tampoco moralistas como Du Vair o eruditos como Guillaume Postel merecen excesiva atención. En cambio, fuera de lo acostumbrado, Ramus tiene un lugar mucho más decisivo que Montaigne y Lèfevre d'Étaples, a quienes el autor dedica una atención similar que a Jean Fernel, a Pontus de Tyard o a Ronsard. Los hispanos, en cambio, son muy apreciados por Leinkauf: Vives, obviamente, aunque también Fox Morcillo aparece muy bien valorado. Vitoria, Las Casas, Molina y, sobre todo, Suárez sirven de contrapunto ( $\mathrm{y}$ hasta de irritation) a los radiantes humanistas.

Quizás la cuestión de la ciencia tenga, para Leinkauf, un interés más limitado que en otros investigadores del Renacimiento. El relieve otorgado a la "Revolución científica", sin ser menor, no alcanza el de otras obras: el lugar de Rheticus, Tycho Brahe o Kepler es menos destacado que el de tantos otros intelectuales ya mencionados, que apenas tienen cabida en libros de estas 
características. Y, en cuanto a la valoración de los teólogos y reformadores, Lutero y Melanchthon adquieren mucha mayor importancia que Calvino, Zwinglio o Beza.

En fin, no sería justo decir que esta extraordinaria obra tiene "carencias": más bien son "querencias" o apetencias del lector quien, tras recorrer las casi dos mil páginas, queda con ganas de más. A título individual, quisiéramos apuntar solo cuatro puntos que hubiéramos querido leer con mayor desarrollo. El primero sería el papel de algunos de los primeros humanistas bizantinos (Plethon, Bessarion...), cuya importancia no queda muy recalcada en la obra (sobre todo, en relación a la siguiente generación: Argyropulos, Trapezuntius...). El segundo es el caso de los pensadores con un pie en la escolástica y otro en el humanismo, o bien aquellos que mezclaban algunas de las tendencias emergentes en esta época: albertismo, nominalismo, lulismo, cábala... que quizás no encajan en las categorías manejadas aquí. El tercero es la figura de Bruno, con la que acaba la obra: es un hermoso colofón, que hubiera podido tener un mayor desarrollo no sólo al tratar cuestiones científicas o cosmológicas, sino también estéticas, gnoseológicas o metafísicas. Quizás suene excesivamente tópico acabar con una sección dedicada a Bruno, pero a nuestro entender hubiera valido la pena. El cuarto punto, en conexión con el anterior, sería una sección final dedicada a la filosofía teorética, cuya estructura había sido anunciada en la Irritation I. Recordando el estudio sobre las teorías del conocimiento de Popkin o el análisis de la metafísica de Lohr (pasando por Platón, Aristóteles y Llull), hubiera sido muy interesante analizar -al igual que había hecho con los demás temas- los diferentes enfoques metafísicos (especialmente desde la Escuela de Padua hasta Bruno).

Por supuesto, cada lector tendrá sus veleidades, aunque no se puede negar el valor de esta obra que es más incisiva en su contenido que no en su estructura (aparentemente tradicional y en la línea de los estudios sobre el Renacimiento y el Humanismo en el siglo XX). Leinkauf, a través de la continua comparación temática y entre autores, a veces incluso desbordante en sus excursos, sabe exprimir los conceptos e iluminar nuevas sendas. Salta con asombrosa agilidad entre siglos, apunta las deudas de unos autores con otros y tiene páginas de una penetración y una sagacidad extraordinarias, que ayudan a comprender algunos de los problemas de fondo de esta época y contribuyen a dar una propuesta interpretativa unitaria. 
Si Francisco Rico (1993) definió el humanismo como un sueño, para la historiografía filosófica sigue existiendo el sueño de lograr un estudio de conjunto que sepa poner en relación a todos los personajes que, por ejemplo, aparecen en las biobliografías preparadas por Wilmott y Schmitt para The Cambridge History. Esperando la publicación de los tres volúmenes de Die Philosophie der Renaissance und des Humanismus (para el Grundriss der Geschichte der Philosophie), podemos decir que falta aún una historia de la filosofía del Renacimiento y del humanismo en la que sepamos por qué incluir o excluir a Cayetano de Vio, Gregor Reisch, Agostino Steuco, Jacob Schegk o John Mair. Y, sobre todo, analizar qué relieve cabe dar a cada uno de ellos. Quizás sea el reto más ambicioso al que el estudioso de este período deba enfrentarse.

Tal vez una sola persona no pueda abordar este proyecto, que sigue siendo el mayor problema historiográfico y conceptual de la época, del que se hacen eco, con singular intensidad, muchos coautores de The Routledge Companion. Queda por dilucidar si existieron intereses humanistas en la escolástica parisina o salmantina, o "renacimientos" que no "renacieron" de las letras clásicas. Cabría preguntarse, en fin, si se puede hablar de un "Humanismo" o de un "Renacimiento" en la Escolástica, el lugar en que quedarían Cayetano o Pedro da Fonseca, cómo cabría calificar el latín y los loci de Cano, o si acaso Vitoria o Las Casas no comparten rasgos con muchos de los que figuran en las monografías bajo el rótulo de "humanistas". Estos y otros interrogantes son el resultado de la lectura de la obra de Leinkauf, un trabajo hercúleo, cincelado con inteligencia y pasión, que deviene el mejor trampolín para proyectar el estudio sobre esta época hacia otras.

Para contribuir a su difusión, ojalá sea traducida a otros idiomas, y suscite muchos debates, pues son dos volúmenes que, por la arrolladora personalidad del autor y su amplitud de miras, pueden marcar una época. En fin, toca a los lectores aceptar el fascinante reto de Leinkauf y estar a la altura a la hora de seguir estudiando el Humanismo y el Renacimiento.

\section{Bibliografía}

AAVV (2005). Il Rinascimento italiano e l'Europa, vol. I, Storia e Storiografia, M. Fantoni (ed.), Treviso: Fondazione Cassamarca - Angelo Colla.

Belda Plans, Juan (2000). La Escuela de Salamanca y la renovación de la teología en el siglo XVI, BAC: Madrid. 
Cantimori, Delio (1985) [1932]. “Sobre la historia del concepto Renacimiento”, en Id., Los historiadores y la historia, Barcelona: Península, 253-294.

Cassirer, Ernst (1927). Individuum und Kosmos in der Philosophie der Renaissance. Leipzig: Teubner.

Colomer, Eusebio (1997). Movimientos de renovación. Humanismo y Renacimiento. Madrid: Akal.

Gandillac, Maurice de (1974). La filosofía del Renacimiento, Madrid: Siglo XXI.

Garin, Eugenio (1981). La revolución cultural del Renacimiento. Barcelona: Crítica.

Garin, Eugenio (1987). La educación en Europa, 1400-1600. Barcelona: Crítica.

Granada, Miguel Á. (2000). El Umbral de la Modernidad. Estudios sobre filosofía, religión y ciencia entre Petrarca y Descartes, Herder: Barcelona.

Hankins, James, ed. (2007). The Cambridge Companion to Renaissance Philosophy. Cambridge: CUP.

Kristeller, Paul O. (1961). Renaissance Thought, the Classic, Scholastic, and Humanist Strains, New York: Harper.

Lagerlund, Henrik; Hill, Benjamin, eds. (2017). The Routledge Companion to Sixteenth Century Philosophy. New York: Routledge.

Leinkauf, Thomas (2017). Grundriss Philosophie des Humanismus und der Renaissance (1350-1600). Hamburg: Meiner, 2 vols.

Rico, Francisco (1993). El sueño del humanismo: de Petrarca a Erasmo. Madrid: Alianza.

Schmitt, Charles B.; Skinner, Quentin, eds. (1988). The Cambridge History of Renaissance Philosophy. Cambridge: CUP.

Recibido: 20/10/2017

Aceptado: 8/01/2018

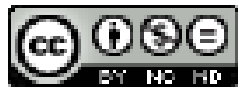

ENDOXA está bajo una licencia de Creative Commons Reconocimiento-NoComercial-SinObraDerivada 4.0 Internacional 